\title{
Novel Method to Monitor the De-Swelling of PNIPAAm Hydrogels of Different Cross-Link Density
}

\author{
Noémi Karnok, Csaba Németh, Viktória Vargha* \\ Department of Physical Chemistry and Materials Science, Budapest University of Technology and Economics, \\ Budapest, Hungary \\ Email: karnokn@gmail.com, nemeth.csaba@mail.bme.hu, *vvargha@mail.bme.hu
}

Received 1 February 2016; accepted 27 March 2016; published 30 March 2016

Copyright (C) 2016 by authors and Scientific Research Publishing Inc.

This work is licensed under the Creative Commons Attribution International License (CC BY). http://creativecommons.org/licenses/by/4.0/

(c) (i) Open Access

\section{Abstract}

The effect of cross-linker (methylene-bis-acrylamide) (MBA) on the volume phase transition, mechanical properties and de-swelling of Poly( $\mathrm{N}$-isopropyl acrylamide-co-methylene-bis-acrylamide) hydrogel (PNIPAAm/MBA hydrogel) was investigated. A new method, namely isothermal thermogravimetry was developed for monitoring de-swelling of PNIPAAm/MBA hydrogel. Monomer/ Cross-linker ratio of the initial monomer composition $R=$ moleNIPAAm $/ \mathrm{moleMBA}$ was introduced. It has been proven earlier that initial monomer composition is close to the copolymer composition; hence $R$ values may be used to express cross-link density. Hydrogels from R10 to R150 were investigated. The results of DSC analysis revealed that the less the cross-linker ratio in the gel (from R10 to R150) the more sharp the temperature range of volume phase transition and the higher its enthalpy. Cross-link density, namely increasing cross-linker content in the copolymer (R from 150 to 10) does not significantly affect the temperature range of volume phase transition. It sets on at $33^{\circ} \mathrm{C}-34^{\circ} \mathrm{C}$, and ends between $35^{\circ} \mathrm{C}$ and $38^{\circ} \mathrm{C}$. Cross-link density has significant effect on compression modulus. By decreasing the ratio of cross-linker (by increasing $R$ from 10 to 150), the compression modulus increases, goes through a maximum, and then decreases. The highest compression modulus was measured for PNIPAAm/MBA hydrogel R20. Hydrogels with cross-linker content between R100 and 30 are strong enough and have their thermoresponsivity. Isothermal thermograms of de-swelling are of similar character for all the gels with different cross-linker content. During the initial stage of de-swelling for gels with higher cross-linker content (R10 - R15) the solute release is quicker than for gels R20 - 150 and the thermograms are drawn out. In the initial stage of de-swelling, i.e. during the first 40 minutes the rate of solute release is the highest for gels R70 - 150. The cross-linker content effects solute release, especially for gels with high crosslinker content. It is noteworthy that gels R10 - 15 release solute quicker than gels R30 - 50 and

\footnotetext{
${ }^{*}$ Corresponding author.
} 
their rate of de-swelling is comparable to that of gels R100 - 150. The novel thermogravimetric method enables the selection of gels based on the rate of solute release and it can also be applied for other cross-linked gels.

\author{
Keywords
}

Intelligent Gel, Poly(N-isopropyl Aceylamide) PNIPAAm, De-Swelling, Thermogravimetry

\title{
1. Introduction
}

Tanaka discovered in 1978 the phenomenon that poly(acryl amide) gel swollen in water replies to a change of the environment (temperature, mix composition etc.) [1]. Nowadays there are special journals on intelligent materials such as the "Journal of Intelligent Material Systems and Structures" or "Smart Materials and Structures".

Gels are between solids and liquids. Solids retain their form, and they can be deformed. Gels in solid state also retain their form, even if they take up high quantity of liquid, and they are deformable. Due to their high liquid content their physico-chemical properties are similar to those of solutions [2].

Gels are colloid systems consisting of two or more components. One component is the liquid or solute, which is in high quantity in the gel (e.g. vitreous body in the eye, muscle, contact lens etc.). The other component is the polymer. The branched polymer network plays the role of a skeleton in the polymer gel hindering the flowing out of the solute from the gel. The solute however hinders the collapse of the polymer network. Gels are used in the separation technique, such as gel-permeation chromatography or gel-electrophoresis. These examples show that gels are mostly polymer gels. Low-molecular gels are mainly based on clay minerals. The driving force of volume change of polymer gels is the endeavor to reach thermodynamic equilibrium. Based on the interaction between the component particles of the gels, physical and chemical gels can be distinguished. In physical polymer gels the network is supported by secondary forces, namely orientational forces between polar groups, inductional forces between polar and apolar groups and dispersional forces between apolar groups. Physical polymer gels are not stable.

If there are hydroxil and amino groups in the polymer molecules, hydrogen bridges can form due to Van der Waals forces. If the molecules posses charge there may arise electrostatic or Coulomb forces between them. In addition interpenetrating or interlocking polymer networks may also form. In chemical polymer gels in the polymer network of infinite molecular mass, the atoms are bonded chemically by covalent bonds. Chemical gels are stable. They may form by cross-copolymerization or by polymerizing a monomer in the presence of the solution of a high molecular mass polymer resulting in interpenetrating or interlocking polymer networks.

In intelligent polymer gels the change on the effect of physical or chemical stimulus takes place in the polymer component. Chemical stimulus may be $\mathrm{pH}$, ions, or chemicals. These stimuli will change the interactions between the polymer chains, or between the polymer chains and the solute molecules. Physical stimuli, such as temperature, electric or magnetic field, mechanical forces also effect the molecular interactions [3]. This type of behavior has been utilized in many fields of application such as thermoresponsive membrane [4], in vitro cell cultivation [5], drug and gene delivery [6], biosensor [7], fluid microchip [8], and many other bio-medical applications [9]-[11]. Garie'py and Leroux reviewed the thermo-responsive gels including poly sacharids, poly (N-isopropyl acrylamide) copolymers, poly(ethylene oxide-b-propylene oxide-b-ethylene oxide), and their copolymers (poloxamer), the poly(ethylene oxide-co-D,L-lactic acid-co-glycolic acid) copolymers, the lyposome based systems and their possibilities of application [12].

The properties of intelligent gels may be modified by coupling their reply to two different types of stimuli, e.g. $\mathrm{pH}$ and temperature [13] [14].

Poly(N-isopropyl acrylamide) (PNIPAAm) is prepared from N-isopropyl acrylamide (NIPAAm) by free radical polymerization (Figure 1).

PNIPAAm hydrogel is one of the most widely studied thermoresponsive hydrogels. It has a lower critical solution temperature LCST) in the vicinity of $34^{\circ} \mathrm{C}$ [15]. It has a negative temperature-susceptibility i.e. on increasing the temperature the volume decreases [3] (Figure 2). Below LCST the gel is hydrophylic, above LCST it becomes hydrophobic. Since the phase transition is near to body temperature, intensive research for bio-medical applications is in progress [16]. 


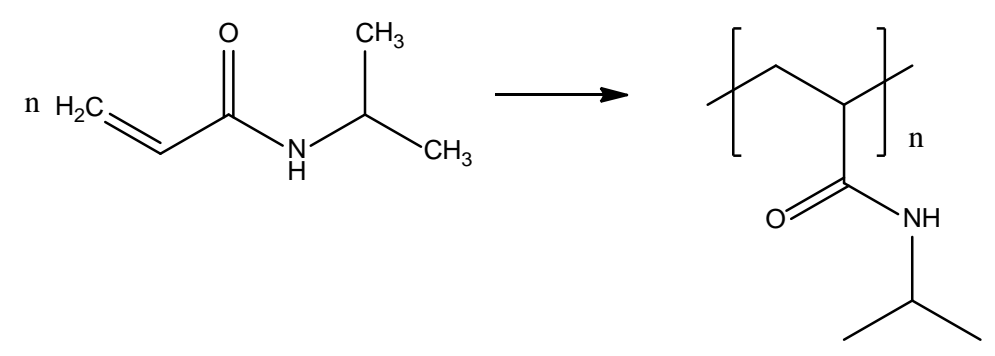

Figure 1. Synthesis of PNIPAAm from NIPAAm.

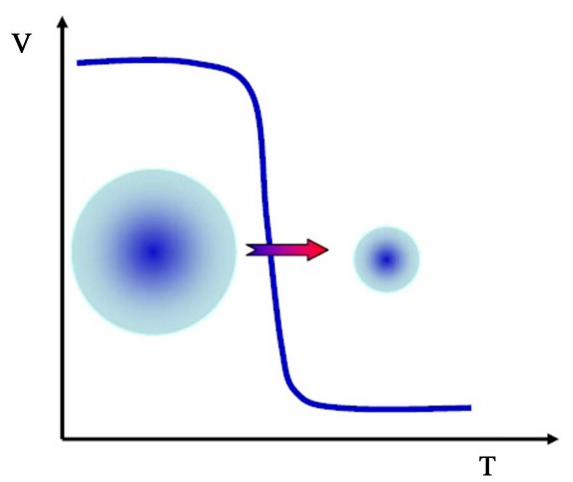

Figure 2. Negative temperature-susceptibility of PNIPAAm hydrogel.

PNIPAAm consists of hydrophylic carbonyl and amide groups and hydrophobic isopropyl groups. In contact with water the hydrophylic groups form hydrogen bridges, while within the polymer chains intramolecular interactions arise. On increasing the temperature conformation of the isopropyl groups takes place and the hydrophobic interactions between the polymer chains dominate. The rivalry of hydrophylic and hydrophobic interactions determines the gel structure [17]-[19]. PNIPAAm hudrogel is neutral; it belongs to the inert gels.

For determining the LCST turbidimetry, calorimetry, light scattering, nuclear magnetic resonance spectroscopy (NMR), oscillation rheometry [20], fluorescence spectroscopy, Fourier transform infrared spectroscopy may be used [21].

Many authors confuse initial monomer composition with cross-linker content or cross-link density of the copolymer. Chetty and co-workers investigated the relation between the initial monomer composition and the composition of the formed cross-linked PNIPAAm hydrogel. It has been found that the copolymer gel composition was very close to the initial monomer composition [20]. Therefore the copolymer cross-link density can also be expressed with the monomer to cross-linker ratio, namely with the $\mathrm{R}$ values, i.e. $\mathrm{R}=$ mole NIPAAM monomer/mole Methylene-bis-acrylamide (MBA) cross-linker in the initial monomer composition.

\subsection{Aim}

Since the possibilities of application of PNIPAAm hydrogels are extremely wide, the effect of cross-link density on the temperature range of phase transition, on the mechanical properties and on swelling and de-swelling has not yet been fully elucidated. Therefore we studied the relation between the cross-linker content and phase transition temperature, compression modulus, rheological properties swelling and de-swelling of PNIPAAm hydrogels. We developed a novel method to monitor de-swelling by isothermal thermogravimetry. The new method enables the selection of the desired composition (monomer to cross-linker ratio) based on the rate of solute release, and it can be extended to investigate other cross-linked hydrogels. Results on the effect of cross-link density on swelling and rheological properties will be discussed in a later publication.

\subsection{Experimental}

The materials used for gel preparation are given in Table 1. PNIPAm was recrystallized two times before use, the other components were used as received. 
Table 1. Materials used for gel preparation.

\begin{tabular}{|c|c|c|c|c|c|}
\hline Material & Abbreviation & Formula & Role & Purity & Supplier \\
\hline N-isopropyl acrylamide & NIPAAm & $\mathrm{C}_{6} \mathrm{H}_{11} \mathrm{NO}$ & monomer & $99 \%$ & Acros Organics \\
\hline N,N'-methylene-bis-acrylamide & MBA & $\mathrm{C}_{7} \mathrm{H}_{10} \mathrm{~N}_{2} \mathrm{O}_{2}$ & cross-linker & $99 \%$ & Sigma-Aldrich \\
\hline Ammonium persulfate & APS & $\left(\mathrm{NH}_{4}\right)_{2} \mathrm{~S}_{2} \mathrm{O}_{8}$ & initiator & $98 \%$ & Sigma-Aldrich \\
\hline N,N,N',N'-tetramethyl-ethylene-diamine & TEMED & $\mathrm{C}_{6} \mathrm{H}_{16} \mathrm{~N}_{2}$ & activator & $99 \%$ & Merck \\
\hline Two-times distilled water & Water & $\mathrm{H}_{2} \mathrm{O}$ & solute & & \\
\hline
\end{tabular}

\subsection{Preparation of Gel Sheets}

Nitrogen gas was bubbled through water for half an hour in order to remove oxygen. The glass plates were cleaned, sealed with silicon rubber and put into the refrigerator to cool to about $5^{\circ} \mathrm{C}$.

1 molar NIPAAm solution, 0.1 molar MBA solution and 0.5 molar APS solution in water were prepared, and put in the refrigerator. The required quantities of the solutions were put in flasks according to Table 2. TEMED was added directly before pouring the solutions between the glass plates. After adding TEMED and homogenization the glass plates were filled with the solution and they were placed into the refrigerator for one week. After one week the gel sheets were removed from the glass plates by rinsing them with water. The gel sheets were transfered into excess water and dialized for removing the monomers. Trace of monomer was checked by UV spectroscopy (UVIKON 930). From the purified gel sheets disks of $7 \mathrm{~mm}$ diameter and $2 \mathrm{~mm}$ thickness were cut and stored in conditioned laboratory.

\subsection{Preparation of Cylinders for Modulus Measurements}

The cleaned cylindric containers and the glass plates were put in the refrigerator. Glass plates greased with silicon served as support underneath the cylindric containers to hinder the solution to flow out. After preparing the solution of the required composition, it was poured into the cylindric containers and treated similarly to the gel sheets. After removing the gelled cylinders from the containers, they were dialized daily until monomer-free.

\section{Methods}

\subsection{Micro DSC}

Temperature range and enthalpy of volume phase transition was determined by Micro DSC III. One disk of dry gel was measured, put into the sample cell, and $500 \mu \mathrm{l}$ double distilled water was put into the reference cell. The temperature range of the scan was $10^{\circ} \mathrm{C}-60^{\circ} \mathrm{C}$ the heating rate $0.5^{\circ} \mathrm{C} / \mathrm{min}$. After having reached the $60^{\circ} \mathrm{C}$ a controlled cooling with $0.5^{\circ} \mathrm{C} / \mathrm{min}$ followed, then a standstill for $120 \mathrm{~min}$ at $10^{\circ} \mathrm{C}$, followed by a second heating to $60^{\circ} \mathrm{C}$ with $0.5^{\circ} \mathrm{C} / \mathrm{min}$. Phase transition is recognized as an endothermic peak between $33^{\circ} \mathrm{C}-34^{\circ} \mathrm{C}$.

\subsection{Modulus Measurement}

Height and diameter of the cylindric gels swollen to equilibrium without load were measured. The load was $5 \mathrm{~N}$ applied as a uniaxial compression with Instron 5543 up to deformation of $10 \%$ of the height of the cylinder. Time of relaxation was $3 \mathrm{~s}$. The deformation of the isotropic, flexible and homogenous probes can be described by the Neo-Hooke law, from which compression modulus was calculated [2].

\subsection{Monitoring De-Swelling}

For the measurements gel disks at equilibrium were used. The thermal analyzer was Perkin Elmer TGA6. Isothermal thermogravimetric measurements took place at $37^{\circ} \mathrm{C}$ in flowing nitrogen. Five parallel measurements were carried ou for each $\mathrm{R}$ values.

\subsection{Calculation of De-Swelling}

For the calculations the accurate dry mass of the disks was needed. It was calculated from the swelling mea- 
Table 2. Initial composition of the PNIPAAm hydrogels.

\begin{tabular}{ccccc}
\hline $\mathbf{R}$ & NIPA $\mathbf{1} \mathbf{~ M}(\mathbf{m l})$ & MBA 0.1 M (ml) & APS 0.5 M (ml) & TEMED (ml) \\
\hline $\mathbf{1 0}$ & 9.769 & 9.769 & 0.430 & 0.0322 \\
$\mathbf{1 5}$ & 11.000 & 7.786 & 0.498 & 0.0374 \\
$\mathbf{2 0}$ & 11.679 & 6.472 & 0.544 & 0.0408 \\
$\mathbf{2 5}$ & 13.844 & 5.537 & 0.576 & 0.0432 \\
$\mathbf{3 0}$ & 14.516 & 4.839 & 0.600 & 0.0450 \\
$\mathbf{5 0}$ & 16.079 & 3.216 & 0.656 & 0.0492 \\
$\mathbf{7 0}$ & 16.857 & 2.408 & 0.684 & 0.0513 \\
$\mathbf{9 0}$ & 17.322 & 1.925 & 0.701 & 0.0525 \\
$\mathbf{1 0 0}$ & 17.491 & 1.749 & 0.707 & 0.0530 \\
$\mathbf{1 5 0}$ & 18.019 & 1.201 & 0.726 & 0.0544 \\
Total & $\mathbf{1 4 8 . 5 1 9}$ & $\mathbf{4 4 . 9 0 2}$ & $\mathbf{6 . 1 2 0}$ & $\mathbf{0 . 4 5 9}$ \\
\hline
\end{tabular}

surements. The equilibrium swelling degree $\left(q_{m}\right)$ was calculated as

$$
q_{m}=\frac{m_{\text {eqswallen gel }}}{m_{\text {dry gel }}}
$$

The accurate dry mass was calculated by dividing the mass of the equilibrium swollen gel weighed in the thermogravimeter $\left(m_{\mathrm{gel}}^{\prime}\right)$ with the equilibrium swelling degree $\left(q_{m}\right)$

$$
m_{\mathrm{dry} \mathrm{gel}}^{\prime}=\frac{m_{\mathrm{gel}}^{\prime}}{q_{m}}
$$

The degree of swelling by mass at any time $\left(q_{m_{t}}^{\prime}\right)$ is calculated by dividing the mass at a given time $\left(m_{\mathrm{t} \_ \text {gel }}^{\prime}\right)$ with the dry mass.

$$
q_{m_{t}}^{\prime}=\frac{m_{\mathrm{t} \_\mathrm{gel}}^{\prime}}{m_{\mathrm{dry} g e l}^{\prime}}
$$

\section{Results}

\subsection{Results of DSC Analysis}

The results of DSC analysis of PNIPAAm/MBA gels with different cross-linker content are represented in Figure 3, the evaluation of peak temperatures and the enthalpy of phase transition is given in Table 3 and Figure 4. From Figure 3 and Table 3 it is clear that the less the cross-linker ratio in the gel (from R10 to R150) the more sharp is the temperature range of volume phase transition. It is noteworthy however that the enthalpy of volume phase transition increases with decreasing cross-linker content (Figure 4). The reason for this is the high concentration of NIPAAm, which is responsible for thermoresponsitivity. It may be concluded that cross-link density, namely decreasing cross-linker content in the copolymer ( $\mathrm{R}$ from 10 to 150 ) does not significantly effect the temperature range of volume phase transition. The onset temperature of phase transition is $33^{\circ} \mathrm{C}-34^{\circ} \mathrm{C}$, the phase transition ends between $35^{\circ} \mathrm{C}-38^{\circ} \mathrm{C}$ (Figure 3 and Table 3 ).

\subsection{Evaluation of Compression Modulus of PNIPAAm Hydrogels with Different Cross-Linker Content}

The results of Compression modulus measurements are represented in Figure 5. 

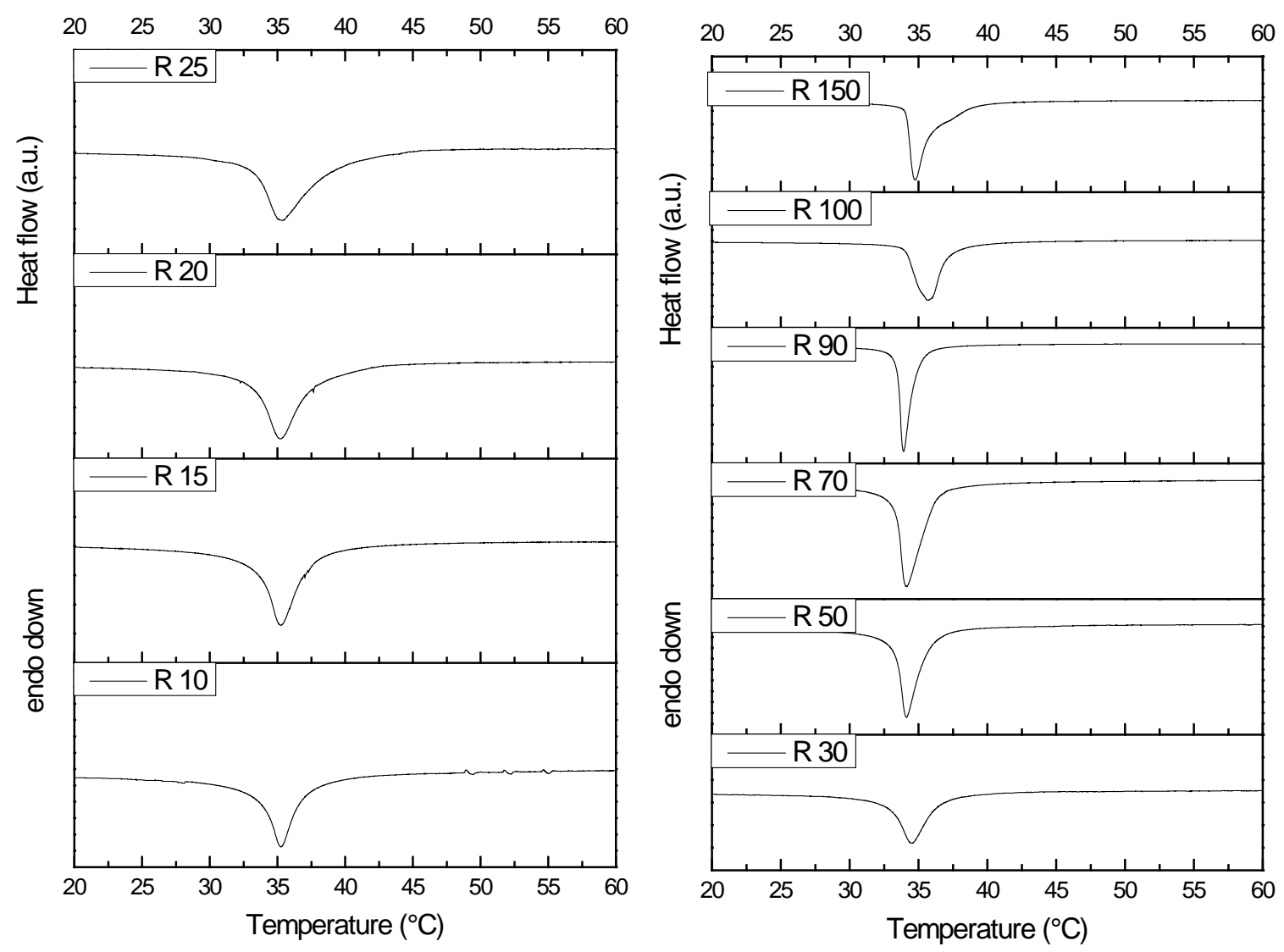

Figure 3. DSC scans for PNIPAAm gels with different cross-linker content.

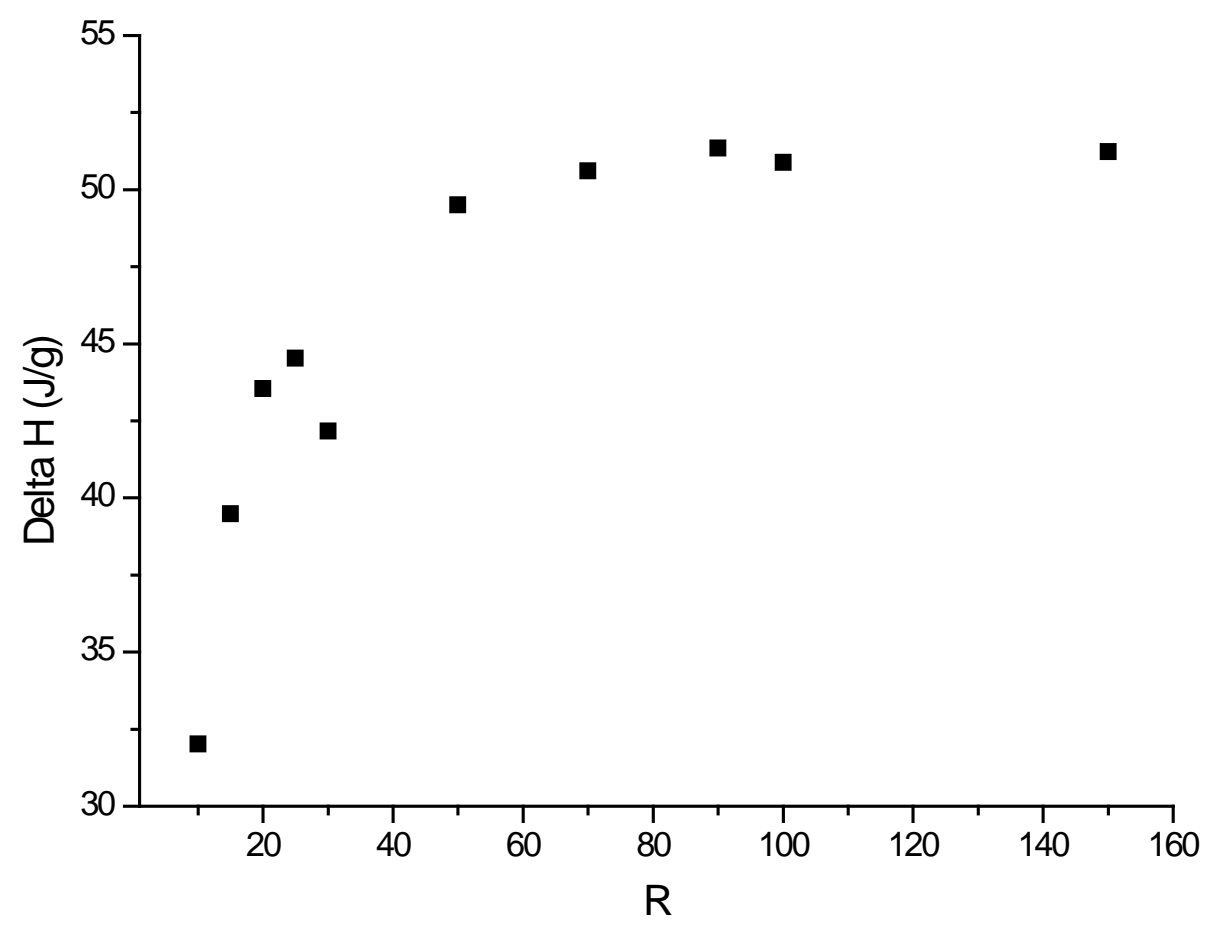

Figure 4. Change of enthalpy of volume phase transition of PNIPAAm/MBA hydrogels with decreasing cross-linker content. 


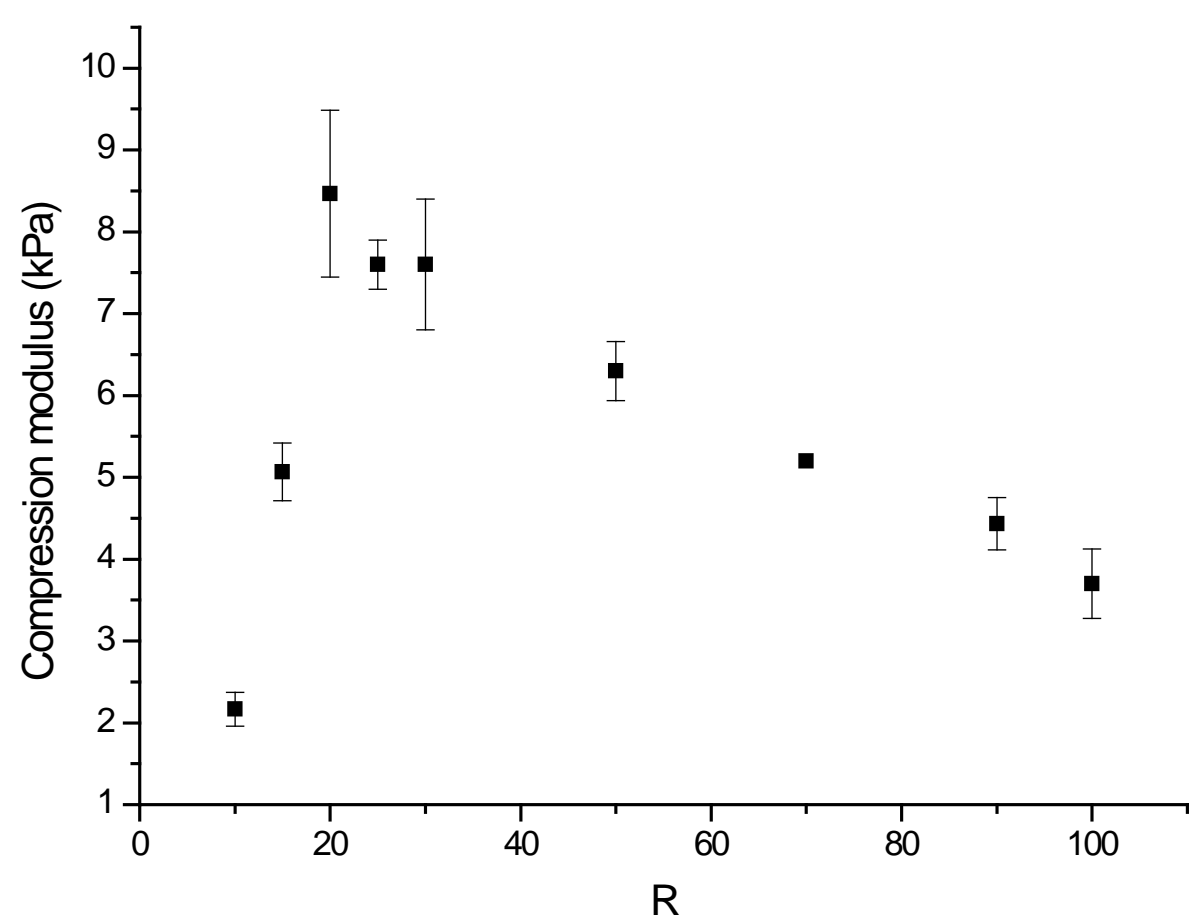

Figure 5. Compression modulus of PNIPAAm/MBA hydrogels with decreasing cross-linker content.

Table 3. Results of DSC analysis of PNIPAAm hydrogels with different cross-linker content.

\begin{tabular}{ccccc}
\hline $\mathrm{R}$ & $\mathrm{T}_{\text {onset }}$ & $\mathrm{T}_{\text {peak }}$ & Tend & Delta H (J/g) \\
\hline 10 & 33.6 & 35.2 & 37.1 & 32.0 \\
15 & 33.5 & 35.2 & 37.5 & 39.5 \\
20 & 33.1 & 35.2 & 37.8 & 43.5 \\
25 & 33.1 & 35.2 & 37.9 & 44.5 \\
30 & 32.8 & 34.5 & 36.6 & 42.2 \\
50 & 33.2 & 34.1 & 35.8 & 49.5 \\
70 & 33.3 & 34.1 & 36.3 & 50.6 \\
90 & 33.4 & 33.9 & 34.9 & 51.3 \\
100 & 33.9 & 35.7 & 37.1 & 50.9 \\
\hline
\end{tabular}

Cross-link density has a significant effect on the compression modulus. By decreasing the ratio of cross-linker (by increasing R from 10 to 150), the compression modulus increases, goes through a maximum, then decreases. Hydrogels with cross-linker content between R 100 and 30 are acceptably strong enough retaining their thermoresponsivity.

\subsection{Evaluation of De-Swelling}

Solute release of PNIPAAm/MBA gels of different cross-linker content was monitored by isothermal thermogravimetry at $37^{\circ} \mathrm{C}$. The results are represented by Figure 6 .

As seen from Figure 6 the process of de-swelling is of similar character for all the gels with different crosslinker content. During the initial stage of de-swelling for gels with higher cross-linker content (R10 - R15) the solute release is quicker than for gels R20 - 150 and is drawn out. In order to compare the de-swelling of the 
N. Karnok et al.
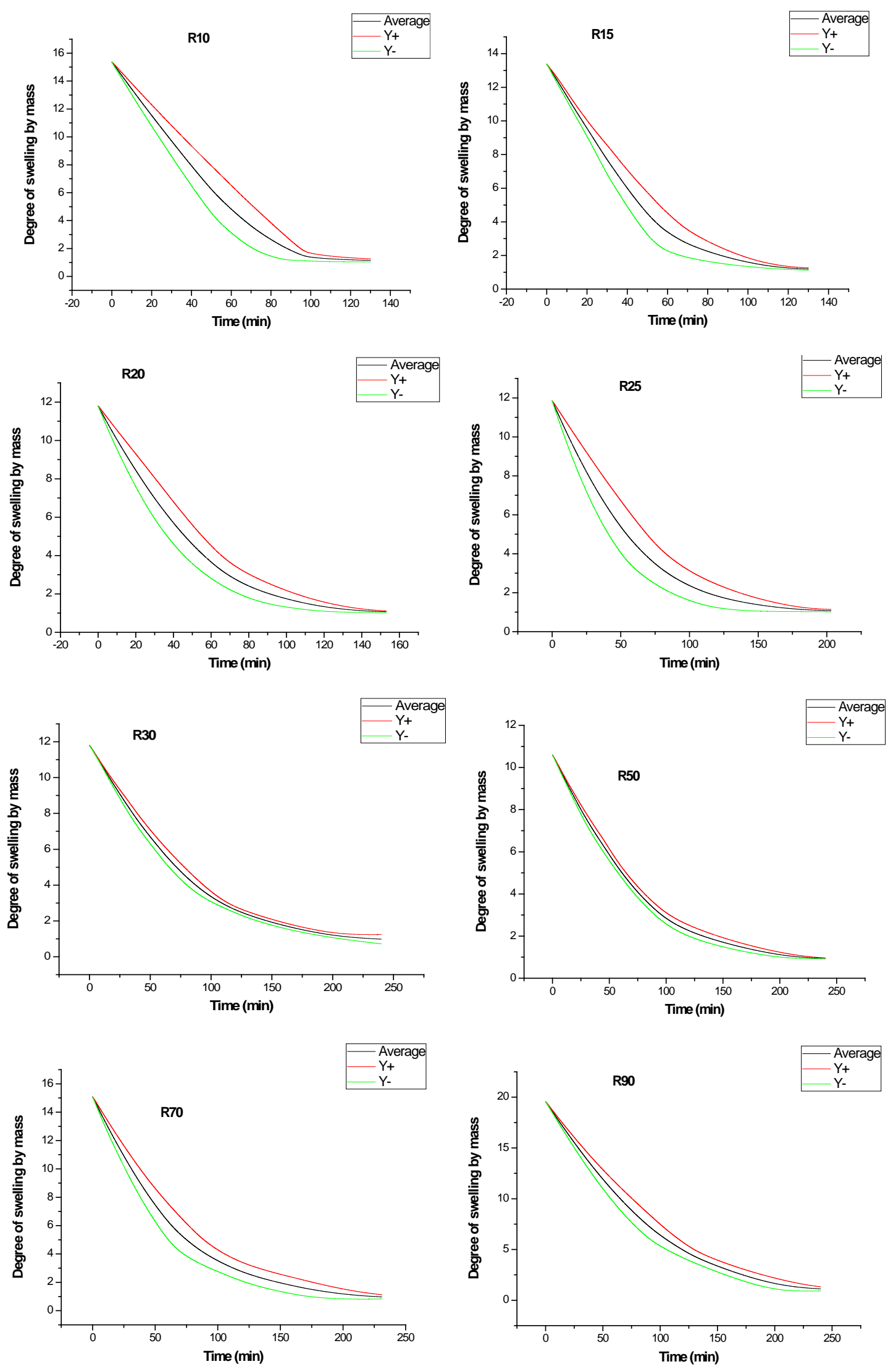

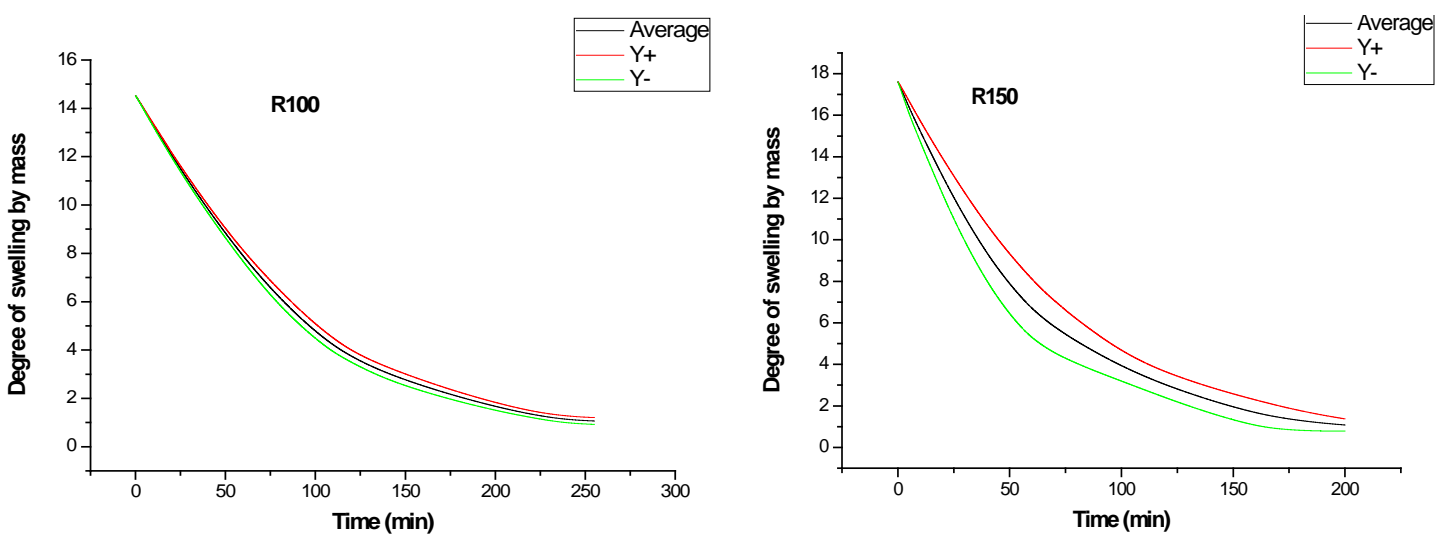

Figure 6. Degree of swelling by mass of PNIPAAm/MBA hydrogels of different cross-linker content versus time.

different gels, trend-lines were fitted to the first 40 minutes of the de-swelling curves. The equations of trendlines fitted to the initial stage ( 1 - 40 minutes) of the de-swelling curves are given in Table 4 . The rate of solute release may be expressed by the steepness (-tan alpha) of the trendlines. Table 3 shows the equations of the trendlines fitted to the initial stage ( 1 - 40 minutes) of the de-swelling curves. The relation between the rate of solute release (-tan alpha) and cross-link density is represented by Figure 7 and Table 5.

In the initial stage of de-swelling, i.e. during the first 40 minutes the rate of solute release is the highest for gels with R70 - 150. The cross-linker content effects solute release, especially in case of high cross-linker ratio. Noteworthy is that gels R10 - 15 release solute quicker than gels R30 - 50 and their rate of de-swelling is comparable to that of gels R100 - 150.

\section{Conclusions}

The effect of the ratio of monomer (NIPAAm) to cross-linker (MBA) on the volume phase transition, on compression modulus and solute release of (PNIPAAm/MBA) hydrogel was investigated. A new method, namely isothermal thermogravimetry was developed to monitor the de-swelling of PNIPAAm/MBA hydrogel of different cross-linker content. Based on the results of DSC analysis it may be concluded that the less the cross-linker ratio in the gel (from R10 to R150), the more sharp the volume phase transition and the higher the enthalpy accompanying it. The reason for this may be the high PNIPAAm content in the copolymer, which is responsible for thermosensitivity. Cross-link density, namely increasing cross-linker content in the copolymer (R from 150 to 10) does not significantly effect the temperature range of volume phase transition. The onset temperature of phase transition is $33^{\circ} \mathrm{C}-34^{\circ} \mathrm{C}$; the phase transition ends between $35^{\circ} \mathrm{C}$ and $38^{\circ} \mathrm{C}$. Cross-link density has a significant effect on the compression modulus. By decreasing the ratio of cross-linker (by increasing $\mathrm{R}$ from 10 to 150 ), the compression modulus increases, goes through a maximum, and then decreases. The highest compression modulus was measured for PNIPAAm hydrogel R20. Hydrogels with cross-linker content between R 100 and 30 are acceptably strong enough and retain their thermoresponsivity.

Isothermal thermograms of de-swelling are of similar character for all the gels with different cross-linker content. During the initial stage of de-swelling for gels with higher cross-linker content (R10 - R15) the solute release is quicker than for gels R20 - 150 and is drawn out. In order to compare the de-swelling of the different gels, trend-lines were fitted to the first 40 minutes of the de-swelling curves. The rate of solute release has been expressed by the steepness (-tan alpha) of the trendlines.

In the initial stage of de-swelling, i.e. during the first 40 minutes the rate of solute release is the highest for gels with R70 - 150. The cross-linker content effects solute release, especially in case of high cross-linker ratio. It is noteworthy that gels R10 - 15 release solute quicker than gels R30 - 50 and their rate of de-swelling is comparable to that of gels R100 - 150.

Finally it can be concluded that PNIPAAm hydrogel R90 has the most favourable properties; it has ideal swelling-de-swelling behavior, a sharp temperature range of volume phase transition and is strong enough based on modulus measurement.

The developed new method of thermogravimetry is able to select hydrogels based on the rate of solute release. The method can be applied to monitor the de-swelling of other types of cross-linked hydrogels. 


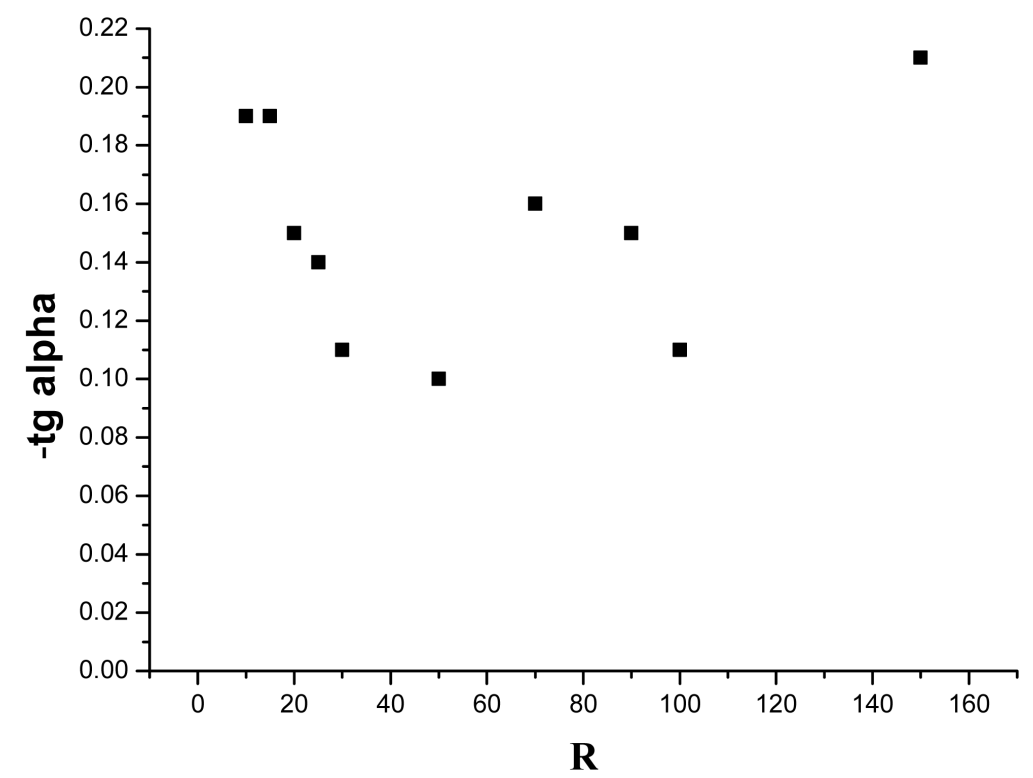

Figure 7. The relation between cross-link density and the rate of solute release (-tg alpha) in the initial stage of de-swelling.

Table 4. Equations of trendlines fitted to the initial stage (1 - 40 minutes) of the de-swelling curves.

\begin{tabular}{ccc}
\hline R10 & Trendline equation & $\mathbf{R}^{2}$ \\
\hline $\mathbf{R} 15$ & $\mathrm{y}=-0.1859 \mathrm{x}+15.3$ & 0.9998 \\
$\mathbf{R 2 0}$ & $\mathrm{y}=-0.1867 \mathrm{x}+13.339$ & 0.9996 \\
$\mathbf{R 2 5}$ & $\mathrm{y}=-0.1524 \mathrm{x}+11.592$ & 0.9973 \\
$\mathbf{R 3 0}$ & $\mathrm{y}=-0.1366 \mathrm{x}+11.69$ & 0.9975 \\
$\mathbf{R} 50$ & $\mathrm{y}=-0.1067 \mathrm{x}+11.78$ & 0.9995 \\
$\mathbf{R} 70$ & $\mathrm{y}=-0.0991 \mathrm{x}+10.536$ & 0.9987 \\
$\mathbf{R} 90$ & $\mathrm{y}=-0.1592 \mathrm{x}+14.953$ & 0.9987 \\
$\mathbf{R 1 0 0}$ & $\mathrm{y}=-0.157 \mathrm{x}+19.497$ & 0.9996 \\
$\mathbf{R} 150$ & $\mathrm{y}=-0.1174 \mathrm{x}+14.475$ & 0.9993 \\
\hline
\end{tabular}

Table 5. The relation between cross-link density and the rate of solute release (-tan alpha) in the initial stage of de-swelling.

\begin{tabular}{ll}
\hline $\mathrm{R}$ & -tan alpha \\
\hline 10 & 0.19 \\
15 & 0.19 \\
20 & 0.15 \\
25 & 0.14 \\
30 & 0.11 \\
50 & 0.99 \\
70 & 0.16 \\
100 & 0.15 \\
150 & 0.11 \\
\hline
\end{tabular}




\section{Acknowledgements}

This work is related to the scientific program "Development of quality-oriented and harmonized R + D + I strategy and functional model at BME” supported by the New Széchenyi Development Plan (Project ID: TÁMOP-4.2.1/B-09/1/KMR-2010-0002).

\section{References}

[1] Tanaka, T. (1978) Collapse of Gels and the Critical Endpoint. Physical Review Letters, 40, 820. http://dx.doi.org/10.1103/PhysRevLett.40.820

[2] Szilágyi, A. (2005) Thermoresponsive Polimer Gels-From Theory to Practice. Ph.D. Thesis, Budapest University of Technology and Economics, Budapest.

[3] Gil, E.S. and Hudson, S.M. (2004) Stimuli-Reponsive Polymers and Their Bioconjugates. Progress in Polymer Science, 29, 1173-1222. http://dx.doi.org/10.1016/j.progpolymsci.2004.08.003

[4] Li, P.F., Ju, X.J., Chu, L.Y. and Xie, R. (2006) Thermo-Responsive Membranes with Cross-Linked Poly(N-isopropylacrylamide) Hydrogels inside Porous Substrates. Chemical Engineering \& Technology, 29, 1333-1339. http://dx.doi.org/10.1002/ceat.200600174

[5] Haraguchi, K., Takehisa, T. and Ebato, M. (2006) Control of Cell Cultivation and Cell Sheet Detachment on the Surface of Polymer/Clay Nanocomposite Hydrogels. Biomacromolecules, 7, 3267-3275. http://dx.doi.org/10.1021/bm060549b

[6] Hoare, T.R. and Kohane, D.S. (2008) Hydrogels in Drug Delivery: Progress and Challenges. Polymer, 49, $1993-2007$. http://dx.doi.org/10.1016/j.polymer.2008.01.027

[7] Chang, D.P., Dolbow, J.E. and Zauscher, S. (2007) Switchable Friction of Stimulus-Responsive Hydrogels. Langmuir, 23, 250-257. http://dx.doi.org/10.1021/la0617006

[8] Sugiura, S., Szilagyi, A., Sumaru, K., Hattori, K., Takagi, T., Filipcsei, G., Zrinyi, M. and Kanamori, T. (2009) OnDemand Microfluidic Control by Micropatterned Light Irradiation of a Photoresponsive Hydrogel Sheet. Lab on a Chip, 9, 196-198. http://dx.doi.org/10.1039/B810717C

[9] Lu, Z.R., Kopečková, P. and Kopeček, J. (2003) Antigen Responsive Hydrogels Based on Polymerizable Antibody Fab Fragment. Macromolecular Bioscience, 3, 296-300. http://dx.doi.org/10.1002/mabi.200390039

[10] Zhang, X.X., Li, J., Gao, J., Sun, L. and Chang, W.B. (2000) Determination of Morphine by Capillary Electrophoresis Immunoassay in Thermally Reversible Hydrogel-Modified Buffer and Laser-Induced Fluorescence Detection. Journal of Chromatography A, 895, 1-7. http://dx.doi.org/10.1016/S0021-9673(00)00590-2

[11] Zhang, X.X., Li, J., Gao, J., Sun, L. and Chang, W.B. (1999) Determination of Doping Methyltestosterone by Capillary Electrophoresis Immunological Analysis with Thermally Reversible Hydrogel and Laser-Induced Fluorescence. Electrophoresis, 20, 1998-2002. http://dx.doi.org/10.1002/(SICI)1522-2683(19990701)20:10<1998::AID-ELPS1998>3.0.CO;2-C

[12] Ruel-Gariepy, E. and Leroux, J.C. (2004) In Situ-Forming Hydrogels-Review of Temperature-Sensitive Systems. European Journal of Pharmaceutics and Biopharmaceutics, 58, 409-426. http://dx.doi.org/10.1016/j.ejpb.2004.03.019

[13] Dagani, R. (1997) Inteligent Gels. Chemical \& Engineering News, 9 June 1997, 26-37.

[14] Kokufuta, E., Wang, B., Yoshida, R., Khokholov, A.R. and Hirata, M. (1998) Volume Phase Transition of Polyelectrolyte Gels with Different Charge Distributions. Macromolecules, 31, 6878-6884. http://dx.doi.org/10.1021/ma971565r

[15] Hirokawa, Y. and Tanaka, T. (1984) Volume Phase Transition in a Nonionic Gel. Journal of Chemical Physics, 81, 6379. http://dx.doi.org/10.1063/1.447548

[16] Hoffman, A.S., Afrassiabi, A. and Dong, L.C. (1986) Thermally Reversible Hydrogels: II. Delivery and Selective Removal of Substances from Aqueous Solutions. Journal of Controlled Release, 4, 213-222. http://dx.doi.org/10.1016/0168-3659(86)90005-2

[17] Lele, A.K., Badiger, M.V., Hirve, M.M. and Mashelkar, R.A. (1995) Thermodynamics of Hydrogen-Bonded Polymer Gel-Solvent Systems. Chemical Engineering Science, 50, 3535-3542. http://dx.doi.org/10.1016/0009-2509(95)00197-D

[18] Schild, H.G. (1992) Poly( $N$-isopropylacrylamide): Experiment, Theory and Application. Progress in Polymer Science, 17, 163-281. http://dx.doi.org/10.1016/0079-6700(92)90023-R

[19] Mumick, P.S. and McCormick, C.L. (1994) Water Soluble Copolymers. 54 N-Isopropylacylamide-co-acrylamide copolymers Ind Rag Reduction: Synthesis, Characterization, and Dilute Solution Behavior. Polymer Engineering \& Science, 34, 1419-1428. http://dx.doi.org/10.1002/pen.760341809

[20] Chetty, A., Kovács, J., Sulyok, Zs., Mészáros, Á., Fekete, J., Domján, A., Szilágyi, A. and Vargha, V. (2013) A Versatile 
Characterization of Poly(N-isopropylacrylamide-co-N,N'-methylene-bis-acrylamide) Hydrogels for Composition, Mechanical Strength, and Rheology. eXPRESS Polymer Letters, 7, 95-105.

http://dx.doi.org/10.3144/expresspolymlett.2013.9

[21] Percot, A., Zhu, X.X. and Lafleur, M. (2000) A Simple FTIR Spectroscopic Method for the Determination of the Lower Critical Solution Temperature of N-Isopropylacrylamide Copolymers and Related Hydrogels. Journal of Polymer Science Part B: Polymer Physics, 38, 907-915.

http://dx.doi.org/10.1002/(SICI)1099-0488(20000401)38:7<907::AID-POLB1>3.0.CO;2-5 